\title{
EVALUASI PRODUKSI RIPPING OVERBURDEN UNTUK MENCAPAI TARGET PRODUKSI 190.000 BCM PADA BULAN MARET 2021 DI PIT CRM PT DUTA ALAM SUMATERA, LAHAT, SUMATERA SELATAN
}

\author{
THE EVALUATION OF OVERBURDEN RIPPING PRODUCTION TO ACHIEVE THE \\ PRODUCTION TARGET OF 190.000 BCM IN MARCH 2021 AT PIT CRM PT DUTA ALAM \\ SUMATERA, LAHAT, SOUTH SUMATRA
}

\author{
Sepriadi $^{1)}$, Subandi Gusman ${ }^{2)}$ \\ ${ }^{1,2)}$ Program Studi Teknik Pertambangan Batubara Politeknik Akamigas Palembang, 30257, Indonesia \\ Corresponding Author E-mail: sepri@pap.ac.id dan subandi.gusman@gmail.com
}

\begin{abstract}
The overburden ripping by Komatsu D155A bulldozer ripper was a main factor of whether or not the overburden target was achieved in March 2021. Based on the data, the overburden production target in March 2021 was not achieved, that was 158,787 BCM from the production plan of 206,654 BCM. It was due to the ripping capability of Komatsu D155A bulldozer ripper in the field which had not been able to work maximally. The ripping actual production was 138,470 BCM from the planned of 190,000 BCM. this ripping production ability decrease was caused by the factor of overburden material type and work efficiency, efforts that could be made to increase effective working time by increasing employee work time discipline with a tolerance of five minutes each time obstacles such as being late for work, being late after a break, resting too soon and stopping before going home. In addition, an increased supervision by foreman or supervisor must be maintained when starting work until the end of each shift. Implenting work time discipline and supervision of operators could increase work efficiency from $61 \%$ to $64 \%$ with a total production of 122,732 BCM. Furthermore, the second improvement was by applying ripping spaces per $3 \mathrm{~m}$ in the working front area of $15 \times 15 \mathrm{~m}$ on sandstone and mudstone materials to reduce the wear on the ripper and not to forcing the engine performance too much. So that the ripper penetration could be increased from an average of $0.64 \mathrm{~m}$ to $0.8 \mathrm{~m}$ resulting in the production of $175,770 \mathrm{BCM}$ ripping. The last improvement was on the two factors or a combination of improvements to work efficiency to be $64 \%$ and an average ripper penetration of $0.8 \mathrm{~m}$, the theoretical calculation of the overburden ripping production was $191.768 \mathrm{BCM}$. thus, the best solution to achieve the ripping overburden target in the following month was by implementing improvements on the combined factors between ripper penetration and work efficiency in pit CRM.
\end{abstract}

Keywords: Ripping, Production, Overburden, Efficiency.

\begin{abstract}
Abstrak: Ripping overburden oleh bulldozer ripper Komatsu D155A merupakan faktor utama tercapai atau tidaknya target produksi overburden pada bulan Maret 2021. Berdasarkan data bahwa produksi overburden pada bulan Maret 2021 belum tercapai yaitu 158.787 BCM dari rencana produksi 206.654 BCM. Hal ini dikarenakan kemampuan ripping oleh bulldozer ripper Komatsu D155A di lapangan belum dapat bekerja maksimal. Produksi aktual ripping adalah 138.470 BCM dari rencana 190.000 BCM. Tentunya penurunan kemampuan produksi ripping ini disebabkan oleh faktor jenis material overburden dan efisiensi kerja yang masih buruk. Terdapat tiga langkah perbaikan yang dilakukan. Perbaikan pertama pada efisiensi kerja, usaha yang dapat dilakukan untuk meningkatkan waktu kerja efektif dengan cara meningkatkan kedisiplinan waktu kerja karyawan dengan toleransi lima menit tiap waktu hambatan seperti terlambat mulai kerja, terlambat setelah istirahat, terlalu cepat beristirahat dan berhenti sebelum pulang. Selain itu peningkatan pengawasan oleh foreman atau supervisor harus tetap terjaga ketika sudah mulai bekerja sampai akhir bekerja tiap shift. Dengan melakukan kedisiplinan waktu kerja dan pengawasan pada operator ini dapat meningkatkan efisiensi kerja dari $61 \%$ menjadi $64 \%$ dengan jumlah produksi 122.732 BCM. Selanjutnya perbaikan kedua pada penetrasi ripper dengan menerapkan spasi ripping per $3 \mathrm{~m}$ pada area front kerja $15 \times 15 \mathrm{~m}$ pada material sandstone dan mudstone untuk mengurangi tingkat keausan pada ripper dan tidak terlalu memaksa kinerja mesin. Sehingga penetrasi ripper dapat meningkat dari rata-rata 0,64 $\mathrm{m}$ menjadi 0,8 $\mathrm{m}$ menghasilkan produksi ripping 175.770 BCM. Terakhir perbaikan yang ketiga pada kedua faktor atau penggabungan perbaikan terhadap efisiensi kerja menjadi $64 \%$ dan rata-rata penetrasi ripper $0,8 \mathrm{~m}$, didapatkan perhitungan teoritis produksi ripping overburden 191.768 BCM. Jadi, solusi yang terbaik agar mampu mencapai target ripping overburden pada bulan selanjutnya dengan melakukan perbaikan terhadap faktor gabungan antara penetrasi ripper dan efisiensi kerja di pit CRM.
\end{abstract}

Kata kunci: Ripping, Produksi, Overburden, Efisiensi. 


\section{PENDAHULUAN}

\subsection{Latar Belakang}

PT Duta Alam Sumatera (PT DAS) merupakan perusahaan yang bergerak dibidang usaha pertambangan batubara untuk melakukan penjualan batubara pada industri pembangkit listrik tenaga uap dalam negeri. Perusahaan ini didirikan dan memulai kegiatan eksploitasi pertama pada tahun 2009. Memiliki luas daerah konsesi, yaitu 357 Ha dan terletak di Desa Tanjung Baru, Desa Tanjung Pinang, Desa Payo, Desa Sukamarga, Desa kebur, Kecamatan Merapi Barat, Kabupaten Lahat, Sumatera Selatan. PT Duta Alam Sumatera memiliki tiga lapisan seam batubara yang diberi nama seam A, seam $\mathrm{B}$, dan seam $\mathrm{C}$. Aktivitas penambangan di PT Duta Alam Sumatera menggunakan sistem penambangan tambang terbuka dengan metode konvensional mining, yaitu dengan alat excavator backhoe dan dump truck sebagai alat utama penambangan. Kegiatan penambangan dilakukan oleh pihak kontraktor, yaitu PT Cahaya Riau Mandiri (PT CRM) selaku pemilik alat berat memiliki kewajiban memenuhi target produksi overburden pada bulan Maret 2021 dengan rencana produksi overburden adalah 206.654 BCM. Pada pit CRM kegiatan penambangan overburden dilakukan dengan cara ripping material overburden terlebih dahulu sebelum dimuat. Kegiatan penggaruan (ripping) tersebut dilakukan oleh satu unit bulldozer ripper Komatsu D155A dengan target ripping 190.000 BCM dan sisanya 16.654 BCM dengan free digging. Aktualnya produksi ripping tersebut tidak tercapai dikarenakan adanya faktor-faktor hambatan yang terjadi di lapangan.

\subsection{Batasan Masalah}

Batasan masalah dalam penelitian ini antara lain:

1. Penelitian ini hanya dibatasi pada alat ripping bulldozer ripper Komatsu D155A saja dengan tidak melibatkan analisis terhadap alat angkut dan alat mekanis lainnya pada bulan Maret 2021 di pit CRM.
2. Penelitian ini hanya pada evaluasi untuk meningkatkan kemampuan produksi ripping overburden dengan meninjau faktor teknis bulldozer ripper Komatsu D155A tersebut tanpa melakukan perhitungan untuk produksi dozing.

3. Faktor-faktor teknis yang diamati pada bulldozer ripper Komatsu D155A di pit CRM hanya pada kedalaman penetrasi ripper, jarak ripping dan cycle time.

4. Perhitungan produksi ripping pada bulan Maret 2021 hanya dilakukan secara teoritis dengan melakukan perbaikan terhadap faktor kedalaman penetrasi ripper dan efisiensi kerja.

\subsection{Tujuan Penelitian}

Tujuan dari penelitian ini antara lain:

1. Mengetahui data plan dan ketercapaian produksi overburden dan ripping bulldozer ripper Komatsu D155A pit CRM bulan Maret 2021.

2. Menghitung secara teoritis perhitungan produksi ripping bulldozer ripper Komatsu D155A di pit CRM pada bulan Maret 2021.

3. Mengevaluasi faktor-faktor yang mempengaruhi produksi ripping bulldozer ripper Komatsu D155A di pit CRM pada bulan Maret 2021.

4. Menghitung secara teoritis produksi ripping bulldozer ripper Komatsu D155A di pit CRM pada bulan Maret 2021 setelah adanya perbaikan.

5. Mengetahui tingkat produksi ripping aktual dan teoritis setelah perbaikan terhadap faktor ketidaktercapaian.

\subsection{Manfaat Penelitian}

Manfaat dari penelitian adalah sebagai solusi penyelesaian masalah agar dapat tercapai target produksi ripping overburden pada bulan selanjutnya oleh alat bulldozer ripper Komatsu D155A di pit CRM site PT Duta Alam Sumatera.

\section{TEORI DASAR}

\subsection{Mekanisme Ripping pada Bulldozer}

$$
\text { Ripping dilakukan dengan }
$$

menggunakan bulldozer yang dilengkapi 
dengan ripper. Ripping bertujuan untuk menghancurkan material (batuan) yang keras sebelum dilakukan penggusuran. Kekuatan ripper tergantung pada kemampuan bahan pembuatnya untuk masuk kedalam tanah dan kekuatan mesin bulldozer yang menarik ripper tersebut. Bulldozer ripper menggunakan hidraulic control, sehingga ripper dapat digerakkan naik turun disesuaikan dengan dalamnya penggalian yang dikehendaki dan keadaan material yang akan digaru. Hasil penggaruan yang baik ditentukan oleh beberapa hal. Hal yang perlu diperhatikan antara lain:

1. Bila keadaan lapangan memungkinkan, tancapkan seluruh gigi ripper sedalam mungkin dengan memakai seluruh kekuatan yang dimiliki bulldozer.

2. Pada waktu menggali dan merobek bagianbagian yang keras harus diambil jalan yang lurus dan pada saat akan melakukan belokan, gigi ripper harus diangkat terlebih dahulu agar ripper tidak terpuntir atau patah, atau terjadi kerusakan pada kerangka.

3. Jika terkait pada benda yang keras, sehingga bulldozer penariknya terhenti, maka ripper diangkat dahulu kemudian diperiksa apakah yang menyebabkan ketidaklancaran tersebut.

4. Agar gigi ripper dapat masuk lebih dalam, dapat diberi pemberat pada badan alat garu untuk membantu tenaga hidrolik pada bulldozer.

5. Kuku ripper (pick) dan shank protector yang telah aus dan tumpul harus diganti atau dipertajam, karena dapat menurunkan produktivitas ripping.

\subsection{Waktu Edar (Cycle Time) dan Produktivitas Bulldozer}

\subsubsection{Waktu Edar (Cycle Time) Bulldozer}

Waktu edar (cycle time) adalah waktu yang dibutuhkan alat untuk melakukan satu siklus kerja. Waktu edar alat bulldozer ripper dapat dilihat dengan pola gerak dari alat tersebut dimulai dari waktu memasukkan shank ke dalam tanah dan menarik material, kemudian waktu tetap yaitu waktu pergantian gigi dan waktu melepaskan atau menarik shank untuk kemudian mundur. Menurut Tenriajeng (2003), waktu edar ripping dapat ditentukan berdasarkan rumus berikut:

$$
\mathrm{CT}=\mathrm{Wf}+\mathrm{Wr}+\mathrm{Z}
$$

Dimana:

$\mathrm{CT}=$ cycle time (detik)

$\mathrm{Wf}=$ waktu kerja bergerak maju (detik)

$\mathrm{Wr}$ = waktu kerja bergerak mundur (detik)

$\mathrm{Z} \quad$ = waktu menurunkan shank (detik)

Waktu tetap (Z) tergantung daripada jenis transmisi dan jumlah tangkai transmisi yang digunakan. Untuk transmissi yang dibutuhkan sesuai dengan kondisi material yang ada di lapangan.

Tabel 2.1 Waktu Tetap (Z) Untuk Produk Komatsu

\begin{tabular}{|c|c|}
\hline Jenis Transmisi & $\mathrm{Z}$ (menit) \\
\hline \multicolumn{2}{|l|}{ 1. Direct Drive : } \\
\hline - $\quad$ Single Lever & 0,10 \\
\hline - Double Lever & 0,20 \\
\hline 2. Torque Flow & 0,05 \\
\hline
\end{tabular}

Sumber: Andi Tenrisukki Tenriajeng, 2003

\subsubsection{Produktivitas Bulldozer}

Menurut Tenriajeng dalam buku pemindahan tanah mekanis tahun 2003 bahwa produktivitas ripping dapat ditentukan dari beberapa variabel diantaranya penetrasi ripper, jarak ripping, cycle time dan efisiensi kerja. Rumus produktivitas ripping sesuai dengan persamaan berikut ini :

$$
\operatorname{Prp}=\frac{\mathrm{P}^{2} \times \mathrm{J} \times 3600 \times \mathrm{FK}}{\mathrm{CT}}
$$

Dimana:

Prp $=$ produksi ripping $(\mathrm{BCM} / \mathrm{jam})$

$\mathrm{P} \quad=$ kedalaman penetrasi (meter)

$\mathrm{J} \quad=$ jarak ripping (meter)

$\mathrm{FK}=$ faktor $\operatorname{koreksi}(\%)$

$\mathrm{CT}=$ cycle time (detik)

\subsection{Faktor-faktor yang Mempengaruhi Produksi Ripping Bulldozer}

Pemilihan alat garu yang sesuai tidak lepas dari studi lapangan dan uji laboratorium mengenai sifat-sifat material, terutama kekuatan batuan. Di lapangan selalu dijumpai 
material dengan ragam kekuatan. Oleh sebab itu, ada material yang sangat mudah digaru, mudah digaru, sulit digaru, sangat sulit digaru atau bahkan tidak dapat digaru. Kemampugaruan merupakan suatu ukuran apakah material dapat digaru, yang kemudian diklasifikasikan berdasarkan tingkat kemudahan penggaruan. Kemampugaruan didasarkan pada sifat-sifat material dan kondisi geologi, seperti kekerasan, kecepatan seismik, struktur, pelapukan dan air tanah, yang diperoleh dari studi lapangan dan uji laboratorium.

Banyak ilmuwan yang mengusulkan sistem klasifikasi kemampugaruan dengan ragam metode dan parameter yang digunakan. Meskipun begitu, para peneliti setuju bahwa kekuatan batuan dan karakteristik diskontinu memiliki peranan yang penting dalam menentukan metode penggalian. Dalam rekayasa batuan, menentukan sifat fisik dan mekanik batuan merupakan inti dalam memperkirakan perilaku suatu massa batuan. Pengaruh sifat batuan tidak hanya digunakan pada pemilihan alat yang sesuai namun juga pada tahap operasi.

\subsubsection{Tipe Batuan}

Tipe batuan tertentu memilki karakteristik tersendiri, maka identifikasi tipe batuan menjadi hal pertama yang mungkin dilakukan untuk memperoleh petunjuk tentang perilaku batuan. Pada umumnya, penggaruan sering dilakukan pada batuan sedimen, yang merupakan batuan yang terbentuk dari partikel-partikel batuan yang sudah ada, baik dari batuan beku, matamorf maupun batuan sedimen itu sendiri.

\subsubsection{Kekerasan atau Kekuatan}

Kekerasan adalah ketahanan dari suatu bidang permukaan halus terhadap tusukan, goresan, abrasi atau pemotongan. Kekerasan material dapat juga dipakai untuk menyatakan besarnya tegangan yang diperlukan untuk menyebabkan kerusakan pada material. Berikut beberapa kekerasan/kekuatan dari beberapa batuan.
Tabel 2.2 Klasifikasi Kuat Tekan Batuan

\begin{tabular}{|c|c|}
\hline Klasifikasi & $\begin{array}{c}\text { Kuat Tekan } \\
(\mathrm{MPa})\end{array}$ \\
\hline Sangat keras & $250-700$ \\
\hline Keras & $100-250$ \\
\hline Keras Sedang & $50-100$ \\
\hline Lunak & $25-50$ \\
\hline Sangat Lunak & $1-25$ \\
\hline
\end{tabular}

Sumber: Bieniawski, 1989

\subsubsection{Kedalaman Penetrasi}

Kedalaman penetrasi bulldozer ripper ditentukan oleh kebutuhan pekerjaan, kekerasan material, ketebalan lapisan, dan intensitas struktur. Idealnya ripping dengan shank standar dilakukan dengan penetrasi maksimum, hal ini menghasilkan produksi ripping yang maksimal. Kedalaman penetrasi single shank ripper dapat mencapai ke dalaman penetrasi maksimal. Pada kondisi material lunak dan ketebalan lapisan tipis lebih baik digunakan multi shank.

\subsubsection{Abrasivitas}

Parameter yang sering diabaikan dalam evaluasi kemampugaruan batuan adalah abrasivitas. Abrasivitas merupakan sifat batuan dalam menggores permukaan material lain. Sifat ini umumnya digunakan sebagai parameter yang mempengaruhi keausan matabor (bit) dan batang bor. Parameter ini sangat penting hubungannya dengan keekonomisan penggunaan alat garu. Dalam estimasi biaya, pengeluaran terbesar terletak pada penggunaan shank dan tip. Karena komponen ini bekerja dengan kontak langsung dan melawan kekuatan batuan saat proses pembongkaran batuan.

\subsubsection{Tingkat Pelapukan}

Pelapukan batuan terjadi karena adanya pengaruh hydrosphere dan atmosphere. Pelapukan bisa terjadi karena disintegrasi mekanis maupun dekomposisi kimia atau keduanya. Pelapukan yang terjadi karena disintegrasi mekanis dapat dilihat dengan adanya retakan batuan atau kekar dan retakan pada belahan (cleavage) butir mineral. Sedangkan pelapukan kimia menghasilkan perubahan kimia pada mineralnya. Karena adanya pelapukan, maka kekuatan, densitas 
dan stabilitas volumetrik batuan akan menurun, sedangkan deformabilitas dan porositas akan meningkat. Oleh sebab itu, tingkat pelapukan merupakan parameter sangat berpengaruh pada kekuatan batuan hubungannya dengan proses penggalian.

\subsubsection{Struktur Batuan}

Salah satu faktor utama yang mempengaruhi perilaku massa batuan adalah struktur seperti kekar, bidang perlapisan, laminasi, belahan dan patahan. Struktur batuan berupa ketidakmenerusan dapat menggambarkan gangguan mekanis pada sifat batuan. Parameter kekar yang harus diukur hubungannya dengan pengaruhnya terhadap kemampugaruan batuan antara lain orientasi kekar, spasi, kemenerusan dan material pengisi.

\subsubsection{Densitas Material}

Densitas juga merupakan faktor yang dipertimbangkan dalam penaksiran kemampugaruan batuan. Tingkat sementasi, sortasi, kekompakan dan ukuran butir dapat ditaksir melalui densitas. Semakin tinggi densitas, maka semakin sedikit pori dalam batuan dan kekuatan ikat antar butir mineral semakin tinggi.

\subsubsection{Efisiensi Waktu}

Besarnya waktu efisiensi kerja dipengaruhi oleh hambatan-hambatan pada saat melakukan pekerjaan. Hambatan terdiri dari hambatan yang dapat dihindari dan hambatan yang tidak dapat dihindari, hambatan yang dapat dihindari berupa menunggu alat dan operator, menunggu material, waktu istirahat lebih awal, waktu kerja setelah istirahat serta berhenti lebih awal sebelum waktu kerja selesai. Sedangkan hambatan yang tidak dapat dihindari pemeriksaan, pengisian bahan bakar dan pemanasan alat, safety talk, gangguan cuaca, perbaikan alat, persiapan operator dan loading point. Untuk mencari waktu kerja efektif didapat pada persamaan berikut:

$$
\mathrm{Wke}=\mathrm{Wt}-(\mathrm{Wtd}+\mathrm{Whd})
$$

Dimana:

Wke = waktu kerja efektif (menit)

$\mathrm{WT}=$ waktu kerja yang tersedia (menit)
Wtd = waktu hambatan yang tidak dapat dihindari (menit)

Whd = waktu hambatan yang dapat dihindari (menit)

Sedangkan untuk mencari nilai efisiensi kerja merupakan perbandingan waktu kerja efektif terhadap waktu yang tersedia menggunakan persamaan berikut:

Dimana:

$$
\mathrm{Ek}=\frac{\mathrm{Wke}}{\mathrm{Wt}} \times 100 \%
$$

Ek = efisiensi kerja $(\%)$

Wke = waktu kerja efektif (menit)

$\mathrm{Wt}=$ waktu kerja yang tersedia (menit)

Efisiensi waktu dapat diklasifikasikan baik jika nilainya 0,90 dan dikatakan buruk jika 0,50 .

Tabel 2.3 Efisiensi Kerja

\begin{tabular}{|c|c|}
\hline Kondisi Kerja & Efisiensi kerja \\
\hline Menyenangkan & 0,90 \\
\hline Baik & 0,83 \\
\hline Cukup & 0,65 \\
\hline Buruk/Jelek & 0,50 \\
\hline
\end{tabular}

Sumber: Andi Tenrisukki Tenriajeng, 2003

\subsection{Tanah Penutup (Overburden)}

Tanah penutup (overburden) merupakan material yang terdapat di permukaan dan sifatnya dapat dikatakan lepas. Overburden terdiri dari tiga jenis material yaitu material top soil, common soil dan rock (Tenriajeng, 2003). Definisi dari ketiga jenis material tersebut adalah sebagai berikut:

\section{Top soil}

Top soil merupakan materi bagian atas yang sifatnya lunak dan mudah digali. Contoh material top soil adalah material ekspenimbunan dan memiliki kedalaman kurang lebih $2 \mathrm{~m}$. Karena sifat dari materi top soil yang lunak dan mudah digali, maka penggaliannya cukup dengan menggunakan excavator backhoe. Material top soil yang digali berupa tanah yang mengandung humus.

2. Common soil

Common soil merupakan material yang sifatnya agak keras dan agak sulit digali, sehingga penggaliannya tidak dapat menggunakan excavator, melainkan terlebih 
dahulu harus diberai (ripping) menggunakan bulldozer ripper. Material yang termasuk common soil adalah shale, siltstone, claystone, sandstone dan lain-lain.

\section{Rock}

Rock merupakan material yang sangat keras dan sulit digali dengan menggunakan alat berat sehingga untuk melepaskan material rock, yaitu dengan peledakan. Material yang termasuk rock adalah granit, andesit dan lainlain.

\subsection{Jenis Volume Tanah Penutup}

Lapisan tanah penutup (overburden) adalah semua lapisan tanah/batuan yang berada diatas dan langsung menutupi lapisan bahan galian berharga sehingga perlu disingkirkan terlebih dahulu sebelum dapat menggali bahan galian berharga tersebut. Pengupasan tanah penutup merupakan pekerjaan awal dalam suatu operasi penambangan. Dalam pekerjaan stripping overburden ini sangat penting agar mendapatkan stripping ratio yang baik dan recovery batubara yang tinggi. Pada tahap ini juga akan dibuat bench-bench sebagai tempat kerja alat berat. Berdasarkan kondisi volumenya, tanah dapat diubah-ubah. Dikenal tiga macam volume tanah, yaitu volume asli (bank), volume lepas (loose) dan volume padat (compacted). Penjelasan dari masing-masing volume di atas adalah :

1. Volume asli (insitu/bank) adalah volume tanah yang belum diganggu dengan alat-alat berat. Biasanya volume ini dijadikan dasar bagi perhitungan tanah. Satuan yang digunakan adalah bank cubic meter (bcm).

3 Volume lepas (loose) adalah volume tanah setelah dibongkar atau dikeruk dari tempat asalnya. Misalnya tanah yang sudah didorong dengan menggunakan bulldozer, diangkut dump truck atau di tempat penimbunan yang belum dipadatkan. Satuan adalah loose cubic meter $(\mathrm{lcm})$.

4 Volume padat (compacted) adalah volume tanah yang sudah ditimbun dan sudah dipadatkan, misal sebagai badan jalan, landasan stockpile batubara dan sebagainya. Satuan yang digunakan adalah compacted cubic meter (ccm).

\subsection{Swelling Factor}

Pengembangan (swelling) adalah persentase pemberaian volume material dari volume asli yang dapat mengakibatkan bertambahnya jumlah material yang harus dipindahkan kedudukan aslinya (Tenriajeng, 2003). Material di lapangan jika digali akan mengalami pengembangan. Pengembangan volume sebelum digali dan volume setelah digali diartikan sebagai faktor pengembangan. Faktor pengembangan juga dapat diketahui dari perbandingan densitas material lepas dan densitas material insitunya. Densitas adalah berat per unit volume dari suatu material. Mengenai swelling factor berbagai karakteristik material dapat dilihat pada. Menurut Tenriajeng (2003), cara menghitung swelling factor dapat dilakukan dengan menggunakan persamaan sebagai berikut :

Dimana:

$$
\mathrm{SF}=\frac{\mathrm{VB}}{\mathrm{VL}}
$$

$\mathrm{SF} \quad=$ swelling factor

$\mathrm{VB}=$ volume bank $(\mathrm{bcm})$

$\mathrm{VL}=$ volume loose $(\mathrm{lcm})$.

\section{METODOLOGI PENELITIAN}

\subsection{Jenis Penelitian}

Penelitian ini dilakukan dengan metode deskriptif dengan berbentuk kuantitatif dan kualitatif

\subsection{Waktu dan Tempat Penelitian}

Penelitian ini dilakukan di PT Duta Alam Sumatera pada April 2021.

\subsection{Metode Penelitian}

Dalam metode penelitian ini terdapat beberapa cara. Pertama yang dilakukan adalah studi pustaka dengan membaca buku atau laporan yang mempunyai kaitan dengan judul. Selain itu, dilakukan juga pengamatan terhadap kondisi lapangan, seperti pengambilan data cycle time bulldozer Komatsu D155A, data kedalaman penetrasi ripper dan jarak ripping yang ada di pit CRM PT DAS.

1. Cara Pengambilan

a. Studi literatur

Studi literatur dilakukan dengan mencari informasi dan memahami teori yang 
berhubungan dengan penelitian ini.

b. Observasi lapangan

Pengamatan ini dilakukan secara langsung di lapangan untuk mendapatkan data cycle time dan kedalaman penetrasi ripper bulldozer ripper Komatsu D155A di area lokasi kerja pit CRM site PT Duta Alam Sumatera.

c. Wawancara

Wawancara dilakukan untuk mencari informasi tentang ruang lingkup area penelitian. Wawancara dengan pihak-pihak yang berkompeten dibidangnya mengenai kondisi di lapangan yang ada. Bertanya mengenai kondisi dan pekerjaan teknis secara langsung di lapangan.

2. Jenis data

Jenis data yang digunakan pada penelitian ini adalah:

a. Data primer

Data primer adalah data yang diperoleh dari melakukan pengamatan langsung ke lapangan dan melakukan wawancara terhadap pegawai setempat yang kompeten, data tersebut diantaranya, yaitu :

1) Data cycle time alat bulldozer ripper Komatsu D155A,

2) Data penetrasi ripper bulldozer ripper Komatsu D155A, dan

3) Data jarak ripping bulldozer ripper Komatsu D155A.

b. Data sekunder

Data sekunder ialah merupakan bagian dari data pendukung yang didapatkan berdasarkan literatur - literatur yang berhubungan dengan permasalahan yang ada. Pengambilan data tergantung dari jenis data yang dibutuhkan, yaitu:

1) Spesifikai alat

Diperoleh dari handbook alat Komatsu maupun buku pemindahan tanah mekanis sebagai penunjang menghitung produktivitas ripping.

2) Data rencana dan ketercapaian produksi ripping overburden bulldozer ripper Komatsu D155A pada bulan Maret 2021.

3) Data hambatan kerja pada bulan Maret 2021 untuk mencari nilai efisiensi kerja yang menjadi faktor koreksi pada perhitungan produkktivitas ripping.

4) Data jumlah jam hujan bulan Maret 2021.

5) Data hasil uji kuat tekan, kuat geser, kandungan silika, tingkat keausan overburden.

6) Data swell factor overburden.

7) Peta lokasi kesampaian daerah PT DAS.

3. Pengolahan data

Data-data yang telah diperoleh kemudian diklasifikasikan berdasarkan jenis data kemudian dilakukan analisis serta perhitungan sesuai dengan kebutuhan dan tujuan dari penelitian ini.

1) Melakukan penyusunan dan perhitungan data cycle time pada alat bulldozer ripper Komatsu D155A sebanyak 60 data. Berikut ini persamaan yang dipakai dalam perhitungan cycle time, yaitu:

$\mathrm{CT}=\mathrm{Wf}+\mathrm{Wr}+\mathrm{Z}$

2) Perhitungan rata-rata cycle time alat tersebut sesuai dengan persamaan berikut ini :

$\mathrm{CT}$ rata-rata $=\frac{\sum \mathrm{CT}}{\mathrm{n}}$

3) Perhitungan rata-rata kedalaman penetrasi ripper alat sesuai dengan persamaan berikut ini:

\section{$\sum$ Kedalaman Penetrasi Ripper}

$\mathrm{n}$

4) Melakukan perhitungan waktu kerja efektif dengan cara waktu kerja yang tersedia dikurang dengan waktu hambatan kerja sesuai dengan persamaan berikut ini:

$$
\mathrm{Wke}=\mathrm{Wt}-(\mathrm{Wtd}+\mathrm{Whd})
$$

5) Melakukan perhitungan nilai efisiensi kerja dengan cara membandingkan antara waktu kerja efektif dengan waktu yang tersedia sesuai dengan persamaan berikut ini:

$$
\mathrm{Ek}=\frac{\mathrm{Wke}}{\mathrm{Wt}} \times 100 \%
$$

6) Melakukan perhitungan produksi ripping alat bulldozer ripper Komatsu D155A dengan memasukan komponen nilai dari cycle time, efisiensi kerja, kedalaman penetrasi ripper dan juga faktor koreksi lalu dimasukkan sesuai dengan rumus produktivitas, yaitu:

$$
\operatorname{Prp}=\frac{\mathrm{P}^{2} \times \mathrm{J} \times 3600 \times \text { Eff } \times \mathrm{SF}}{\mathrm{CT}}
$$


7) Melakukan pengolahan data dengan menggunakan analisis grafik mengenai tingkat perbandingan produksi ripping bulldozer ripper Komatsu D155A dengan menggunakan aplikasi microsoft office excel 2007.

4. Analisis hasil pengolahan data

Pada tahap analisis pengolahan data dan perhitungan menggunakan aplikasi dari microsoft office excel 2007 agar didapat hasil perhitungan data yang akurat. Hasil pengolahan dan perhitungan data ini digunakan untuk memberikan alternatif penyelesaian masalah atau solusi sebagai acuan membahas permasalahan yang telah dikemukakan dengan membuat sebuah penyusunan langkah permasalahan secara sistematis, faktual, dan cermat. Tahap ini juga mengacu kepada studi pustaka sebagai pelengkap dan sebagai korelasi data yang sudah didapatkan di lapangan sehingga tercipta suatu solusi yang tepat terhadap permasalahan yang ditemui dilapangan.

5. Kesimpulan dan saran

Berdasarkan analisis hasil pengolahan data, kemudian ditarik suatu kesimpulan dari penelitian yang dilakukan sehingga bisa memberikan masukan dan saran kepada perusahaan. Dimana kesimpulan menjawab apa yang menjadi tujuan dari penelitian ini.

\section{HASIL DAN PEMBAHASAN}

\subsection{Plan dan Ketercapaian Produksi Overburden dan Ripping Bulldozer Ripper Komatsu D155A Pit CRM Maret 2021}

Ripping overburden oleh bulldozer ripper Komatsu D155A merupakan faktor utama tercapai atau tidaknya target produksi overburden pada bulan Maret 2021 di pit CRM. Berdasarkan data sekunder, plan produksi overburden pada bulan Maret 2021 adalah $206.654 \mathrm{BCM}$ dengan plan ripping adalah $190.000 \mathrm{BCM}$ sedangkan sisanya free digging. Aktualnya jumlah bulldozer ripper Komatsu D155A di pit CRM untuk ripping overburden hanya ada satu unit yang melayani lima fleet PC 400 yang menyebabkan adanya waktu delay karena travel front dan berpengaruh terhadap penurunan produktivitasnya. Metode ripping yang digunakan cross ripping agar menghasilkan fragmentasi berukuran $20 \mathrm{~cm}$. Luas tiap front kerja ripping adalah $15 \mathrm{~m} \times 15 \mathrm{~m}$ dengan spasi ripping $1,5 \mathrm{~m}$ dan kedalaman rata-rata penetrasi ripper $0,64 \mathrm{~m}$.

Dengan demikian produksi overburden belum tercapai, saat ini produksi sebesar 158.787 BCM. Hal ini dikarenakan kemampuan ripping bulldozer Komatsu D155A di lapangan belum bisa bekerja maksimal. Produksi aktual ripping 138.470 $\mathrm{BCM}$ atau $73 \%$. Tentunya penurunan produksi ini disebabkan oleh faktor jenis material overburden dan efisiensi kerja yang masih buruk. Jenis material overburden yang ada disana sebagian besar didominasi oleh sandstone dan mudstone. Faktor kedua adalah penurunan efisiensi kerja yang dikarenakan oleh displin kerja karyawan dan pengawasan oleh foreman yang kurang baik.

4.2 Menghitung Secara Teoritis Produksi Ripping Bulldozer Ripper Komatsu D155A Di Pit CRM Maret 2021

Perhitungan produktivitas ripping secara teoritis pada bulan Maret 2021 terlebih dahulu dengan mengambil data primer dan sekunder yang menjadi komponen atau variabel dalam perhitungan produksi ripping. Data primer yang diambil adalah cycle time dan penetrasi ripper. Sedangkan data sekunder berupa faktor koreksi seperti nilai efisiensi kerja dan swelling factor. Dari data-data ini kemudian dilakukan penyusunan dan pengolahan data dengan menggunakan program microsoft office excel 2007 agar mendapatkan hasil perhitungan yang baik. Berdasarkan hasil perhitungan produksi ripping secara teoritis pada bulan Maret 2021 maka didapatkan produksi ripping overburden 112.499 BCM. sehingga dapat disimpulkan secara perhitungan teoritis saja tingkat ketercapaian hanya 59\% sedangkan plan ripping $92 \%$ dari jumlah volume overburden. Jadi, hal ini perlu dilakukan evaluasi dan perbaikan terutama pada variabel penetrasi ripper dan efisiensi kerja agar pada bulan 
selanjutnya produksi ripping overburden dapat tercapai.

\subsection{Faktor Penyebab Ketidaktercapaian Produksi Ripping Overburden}

Faktor-faktor penyebab tidak tercapainya produksi ripping overburden pada bulan Maret 2021 sebagai berikut :

\subsubsection{Penetrasi Ripper}

Hasil pengukuran di lapangan rata-rata kedalaman penetrasi ripper bulldozer ripper Komatsu D155A di pit CRM 0,64 m. Padahal secara aktual panjang keseluruhan shank ripper mencapai $0,9 \mathrm{~m}$. Ripping $\mathrm{OB}$ di pit CRM ini dilakukan pada overburden jenis sandstone dan mudstone pada formasi muara enim. Berdasarkan studi literatur dari sebuah jurnal bahwa nilai kuat tekan (UCS) untuk jenis batuan sandstone 7,4 $\mathrm{MPa}$ sedangkan mudstone jenis claystone memiliki kuat tekan 3,4 MPa. Menurut Sahu tahun 2012 berdasarkan nilai kuat tekan tersebut, maka kedua overburden ini dikategorikan pada jenis penggaruan keras (hard ripping) (Tabel 2.1). Oleh karena itu, jika mesin penarik (bulldozer) dipaksakan untuk melakukan penetrasi ripper pada kedalaman yang lebih lagi, maka hal yang akan terjadi sebagai berikut :

1. Pengurangan umur alat

Berdasarkan data rencana jam kerja alat pertahun unit bulldozer ripper Komatsu D155A adalah 2000 jam/tahun. jika dihubungkan dengan kondisi kerja aktual di lapangan, yaitu melakukan ripping dan dozing pada material keras secara terus-menerus untuk melayani lima fleet alat gali muat, maka jika ini tetap dipaksakan aktual di lapangan akan dapat menyebabkan penurunan tenaga bahkan kerusakan pada mesin pertahun sehingga umur alat menjadi berkurang. Jika rencana 2.000 jam pertahun dibagi dengan total 12.000 jam pada kondisi kerja aktual tersebut, maka umur ekonomis alat hanya 6 tahun. Oleh karena itu, aktual di lapangan melakukan penetrasi ripper rata-rata $0,64 \mathrm{~m}$ dengan tidak terlalu memaksakan ripping dan dozing secara rutin atau dengan kata lain ada senggang waktu mesin untuk beristirahat dengan tujuan agar performa mesin tetap terjaga sehingga umur alat ekonomis yang direncanakan oleh PT CRM bisa mencapai lebih dari 8 tahun. Agar umur alat ini dapat terealisasi menjadi lebih dari 8 tahun maka di lapangan perlu dikontrol dengan melakukan pengawasan dan koordinasi yang dilakukan antara foreman dan operator dalam setiap operasinya.

2. Keausan pada ripper

Hal ini disebabkan karena pengaruh kuat tekan, kuat geser dan kandungan silika yang dimiliki oleh sandstone dan claystone di pit CRM. Dengan demikian, PT CRM membatasi kedalaman penetrasi ripper ratarata 0,64 agar tingkat keausan perjam yang ditimbulkan dapat diminimalisir sehingga menghemat biaya pembelian ripper baru dan perawatan.

\subsubsection{Efisiensi Kerja}

Efisiensi kerja digunakan untuk mengetahui berapa persen waktu kerja yang efektif terhadap waktu kerja yang tesedia. Efisiensi kerja ini merupakan salah satu faktor penyebab tidak tercapainya produksi ripping overburden pada bulan Maret 2021 di pit CRM. Hasil data realisasi yang didapatkan dari mine planner PT CRM Bulan Maret 2021 waktu kerja tersedia di PT Cahaya Riau Mandiri job site PT Duta Alam Sumatera adalah $20 \mathrm{jam} / \mathrm{hari}$ dengan waktu efektif 12,3 jam/hari. Dimana pada pekerjaan dibagi dengan dua shift kerja setiap harinya. Efisiensi kerja yang didapatkan pada penelitian ini yaitu $61 \%$. Berdasarkan data tersebut efisiensi kerja ini termasuk dalam kategori buruk. Sehingga efisiensi kerja ini perlu ditingkatkan agar target produksi ripping overburden dapat tercapai.

\subsection{Perhitungan Secara Teoritis Produksi Ripping Setelah Perbaikan Terhadap Faktor Ketidaktercapaian}

Agar produksi ripping tercapai, maka dilakukan evaluasi pada tiga jenis perhitungan produksi ripping pada perbaikan terhadap faktor hambatan, yaitu:

\subsubsection{Perbaikan Efisiensi Kerja}

Perbaikan efisiensi kerja dapat dilakukan dengan cara mengubah atau mentoleransi semua waktu hambatan yang dapat dihindari menjadi lima menit. Usaha 
yang dapat dilakukan untuk meningkatkan waktu kerja efektif dengan cara meningkatkan kedisiplinan waktu kerja karyawan seperti tidak terlambat mulai kerja, tidak terlambat setelah istirahat, tidak terlalu cepat beristirahat dan tidak berhenti sebelum pulang. Peningkatan pengawasan oleh foreman atau supervisor ketika sudah mulai bekerja sampai akhir bekerja tiap shift. Dengan melakukan kedisiplinan waktu kerja dan pengawasan pada operator ini dapat meningkatkan efisiensi kerja. Untuk mencapai keberhasilan akan hal ini maka dibutuhkan juga suatu kontrol administrasi. Dalam hal monitoring administrasi dapat dilakukan dengan pengisian ritase oleh operator pada tiap shift. Pada ritase ini dituliskan catatan operasional, hambatan kerja dan waktu tidak beroperasi sehingga hasil ritase ini dapat dievaluasi perhari. Waktu efektif kerja perhari menjadi 12,8 jam. Hal ini berpengaruh juga pada tingkat keausan ripper terhadap waktu kerja yang sebelumnya bekerja pada lapisan sandstone mencapai 70 $\mathrm{cm} /$ hari dengan waktu $12,8 \mathrm{jam} / \mathrm{hari}$ dengan tingkat keausan menjadi $74 \mathrm{~cm} /$ hari sedangkan pada lapisan claystone sebelumnya 1,92 $\mathrm{cm} /$ hari menjadi 2,04 cm/hari.

Secara teoritis dengan mengganti nilai efisiensi kerja dari $61 \%$ menjadi $64 \%$ didapatkan produksi ripping overburden 130.541 BCM/bulan.

\subsubsection{Perbaikan Penetrasi Ripper}

Berdasarkan dari spesifikasi handbook Komatsu dan aktual di lapangan bahwa panjang ripper dari bulldozer ripper Komatsu D155A yang maksimal untuk penetrasi adalah $0,9 \mathrm{~m}$. Oleh karena itu, penetrasi ripper dimungkinkan dapat ditingkatkan dari rata-rata 0,64 m menjadi 0,8 m. Solusi teknis yang lain adalah dengan menerapkan spasi ripping $3 \mathrm{~m}$ pada area front kerja $15 \mathrm{~m} \times 15 \mathrm{~m}$ dengan jenis material overburden sandstone dan mudstone. Tentunya hal ini berguna untuk mengurangi tingkat keausan pada ripper dan tidak terlalu memaksa kinerja mesin. Ketika proses loading alat gali muat membantu untuk menghancurkan lagi material hasil ripping sebelum dimuat agar material yang diangkut relatif masih berukuran kecil atau diameter 20 $\mathrm{cm}$.. Setelah mengubah nilai penetrasi ripper menjadi $0,8 \mathrm{~m}$, maka secara teoritis hitungan produksi ripping overburden adalah 175.770 $\mathrm{BCM} /$ bulan. Ini artinya terjadi peningkatan ketercapaian $92 \%$ dari plan ripping.

\subsubsection{Perbaikan Efisiensi Kerja dan Penetrasi Ripper}

Perbaikan terakhir dengan cara menggabungkan secara bersamaan perbaikan terhadap efisiensi kerja dan penetrasi ripper. Cara ini solusi terbaik untuk mencapai produksi ripping overburden jika dapat diterapkan pada pit CRM. Dari masing-masing hasil perbaikan terhadap kedua faktor tersebut, maka didapatkan efisiensi kerja $64 \%$ dan ratarata kedalaman penetrasi ripper $0,8 \mathrm{~m}$. Kemudian dilakukan perhitungan secara teoritis produksi ripping overburden, yaitu dengan hasil $191.768 \mathrm{BCM} /$ bulan sehingga tingkat ketercapaian produksi ripping bisa melebihi $100 \%$ dari plan. Tentunya kedua faktor inilah yang harus segera diterapkan dan dijaga secara terus-menerus guna mencapai target produksi ripping overburden pada bulan selanjutnya di pit CRM site PT Duta Alam Sumatera.

\subsection{Tingkat Produksi Ripping Aktual dan Teoritis Setelah Perbaikan Terhadap Faktor Ketidaktercapaian}

Target produksi ripping overburden 190.000 BCM dengan realisasi ketercapaian 138.470 BCM dengan persentase $73 \%$ dari plan ripping. Perhitungan produksi ripping secara teoritis sebelum melakukan perbaikan adalah 112.449 BCM. Selisih produksi ripping overburden antara realisasi dengan hitungan teoritis sebelum perbaikan dikarenakan produksi realisasi menggunakan timbangan rata-rata ritase sedangkan hitungan teoritis mengacu pada persamaan rumus produktivitas ripping dari Tenriajeng sehingga produksi realisasi ketercapaian ripping overburden lebih besar daripada hitungan teoritis. Perbaikan pertama pada efisiensi kerja saja dari $61 \%$ menjadi $64 \%$ menghasilkan produksi ripping 122.732 BCM

Selanjutnya perbaikan kedua pada penetrasi ripper dari rata-rata $0,64 \mathrm{~m}$ menjadi 0,8 m dengan produksi $175.770 \mathrm{BCM}$. Ketiga 
perbaikan pada kedua faktor pada efisiensi kerja $64 \%$ dan rata-rata penetrasi ripper $0,8 \mathrm{~m}$, maka didapatkan perhitungan secara teoritis produksi ripping overburden 191.768 BCM. Jadi, berdasarkan gambar 4.1, maka hasil evaluasi dan perbaikan teoritis untuk memberikan solusi yang terbaik agar mampu mencapai target ripping overburden pada bulan selanjutnya dengan melakukan perbaikan terhadap faktor gabungan antara penetrasi ripper dan efisiensi kerja di pit CRM.

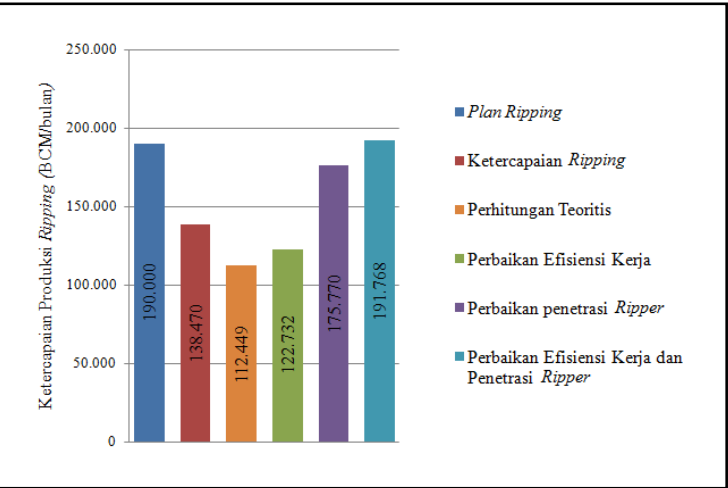

Gambar 4.1 Produksi Ripping Overburden Maret 2021

\section{KESIMPULAN DAN SARAN}

\subsection{Kesimpulan}

Dari pembahasan tersebut, maka dapat disimpulkan

1. Berdasarkan data plan overburden untuk lima fleet pada bulan Maret 2021 adalah 206.654 BCM dengan plan ripping 190.000 BCM atau 92\%. Produksi aktual overburden tidak tercapai, yaitu 158.787 BCM/bulan sedangkan produksi aktual ripping overburden adalah 138.470 BCM/bulan.

2. Hasil perhitungan produksi ripping overburden secara teoritis pada bulan Maret 2021 adalah 112.499 BCM/bulan.

3. Faktor yang mempengaruhi kemampuan produksi ripping overburden disebabkan oleh jenis material overburden yang berpengaruh pada penetrasi ripper dan efisiensi kerja yang masih buruk.

4. Hasil perhitungan produksi ripping overburden secara teoritis setelah perbaikan pada faktor ketidaktercapaian, antara lain sebagai berikut:

a. Perbaikan efisiensi kerja dari $61 \%$ menjadi $64 \%$ didapatkan produksi ripping overburden adalah 122.732 BCM/bulan.

b. Perbaikan penetrasi ripper menjadi 0,8 $\mathrm{m}$ maka secara teoritis produksi ripping overburden adalah $175.770 \mathrm{BCM} / \mathrm{bulan}$.

c. Perbaikan terhadap efisiensi kerja dan penetrasi ripper. Dengan efisiensi kerja $64 \%$ dan rata-rata penetrasi ripper $0,8 \mathrm{~m}$, maka didapatkan perhitungan secara teoritis produksi ripping overburden 191.768 BCM/bulan.

5. Berikut ini tingkat produksi ripping overburden secara plan, aktual dan hasil evaluasi perbaikan pada faktor ketidaktercapaian di pit CRM Maret 2021 :

a. Produksi ripping overburden plan adalah 190.000 BCM/bulan.

b. Produksi ripping overburden aktual adalah 138.470 BCM/bulan.

c. Produksi ripping overburden pada perbaikan efisiensi kerja adalah 122.732 BCM/bulan.

d. Produksi ripping overburden pada perbaikan penetrasi ripper adalah 175.770 BCM/bulan.

e. Produksi ripping overburden pada perbaikan pada kedua faktor adalah 191.768 BCM/bulan.

\subsection{Saran} disarankan:

Dari pembahasan tersebut, maka dapat

1. Usaha yang harus dilakukan untuk meningkatkan waktu kerja efektif dengan cara meningkatkan kedisiplinan waktu kerja karyawan dan toleransi waktu lima menit terhadapa hambatan kerja yang dapat dihindari seperti terlambat mulai kerja, terlambat setelah istirahat, terlalu cepat beristirahat dan berhenti sebelum pulang.

2. Perbaikan penetrasi ripper dapat ditingkatkan dengan menerapkan spasi ripping $3 \mathrm{~m}$ pada jenis material overburden sandstone dan mudstone agar tenaga mesin 
penarik (bulldozer) tetap terjaga dan tingkat keausan pada ripper dapat berkurang.

\section{DAFTAR PUSTAKA}

Abduh, Muhammad, Syamsul Komar, dan Mukiat. 2017. Pengaruh Kekuatan Batuan dan Komposisi Silika Terhadap Tingkat Keausan Mata Garu (Ripper) Dalam Proses Pembongkaran Lapisan Overburden Tambang Batubara PT Muara Alam Sejahtera Kabupaten Lahat Sumatera Selatan. Jurnal Pertambangan. Vol. 1 No. 5.

Akmal, A., dan Sepriadi. 2020. Kajian Teknis Kemantapan Lereng Menggunakan Metode Slope Mass Rating dan Perhitungan Faktor Keamanan Lereng Menggunakan Software Geostudio Slope/W 2012 dan Rocscience Slide V.6 di Pit Barat PT Prima Indojaya Mandiri. Jurnal Teknik Patra Akademika. Vol. 10 No. 2.

Bieniawski, Z.T. 1989. Engineering Rock Mass Classification A Complete Manual for Engineers and Geologist in Mining, Civil and Petroleum Engineering. New York: John Wiley \& Sons.

Fredrick, Gregorius. 2016. Evaluasi Kemampuan Produksi Ripping Dozzer Ripper D375 Untuk Mencapai Target Produksi Batubara 180.000 Ton Batubara Bulan Oktober Di Tambang Air Laya Extension Timur Front Limoa PT Bukit Asam (Persero), Tbk. Jurnal Mineral Vol. 1 No. 1.

Indonesianto, Yanto. 2016. Pemindahan Tanah Mekanis. Yogyakarta: Seri Tambang Umum.

Komatsu. 2009. Specifications and Application Handbook Edition 30. Japan: Komatsu.

Prodjosumarto, Partanto. 1996. Pemindahan Tanah Mekanis. Bandung: Institut Teknologi Bandung.
PT United Tractors. 2020. Manajemen Alatalat Berat. Jakarta : PT United Tractors.

Sahu, R, K. 2012. Application Of Ripper Dozer Combination In Surface Mines: Its Applicability And Performance Study. Rourkela: Department Of Mining Engineering National Institute Of Technolgy.

Sudjana. 1996. Metode Statistika. Bandung: Sinar Baru Algasindo.

Tenriajeng, Andi Tenrisukki. 2003. Pemindahan Tanah Mekanis. Jakarta: Guna Darma. 